\title{
Optimizing ZnO nanoparticle surface for bulk heterojunction hybrid solar cells
}

Shuyan Shao, Kaibo Zheng, Karel Zidek, Pavel Chabera, Tonu Pullerits and Fengling Zhang

\author{
Linköping University Post Print
}

\section{Tweet}

N.B.: When citing this work, cite the original article.

Original Publication:

Shuyan Shao, Kaibo Zheng, Karel Zidek, Pavel Chabera, Tonu Pullerits and Fengling Zhang, Optimizing ZnO nanoparticle surface for bulk heterojunction hybrid solar cells, 2013, Solar Energy Materials and Solar Cells, (118), 43-47.

http://dx.doi.org/10.1016/j.solmat.2013.07.046

Copyright: Elsevier

http://www.elsevier.com/

Postprint available at: Linköping University Electronic Press

http://urn.kb.se/resolve?urn=urn:nbn:se:liu:diva-100908 


\section{Optimizing ZnO nanoparticle surface for bulk heterojunction hybrid solar cells}

Shuyan Shao ${ }^{\mathrm{a}, *}$, Kaibo Zheng ${ }^{\mathrm{b}}$, Karel Zidek ${ }^{\mathrm{b}}$, Pavel Chabera ${ }^{\mathrm{b}}$, Tõnu Pullerits ${ }^{\mathrm{b}}$, Fengling Zhang $^{\mathrm{a}}$

${ }^{a}$ Biomolecular and Organic Electronics, Department of Physics, Chemistry and Biology

Linköping University, 58183 Linköping, Sweden

${ }^{\mathrm{b}}$ Department of Chemical Physics, Lund University, Box 124, 22100, Lund, Sweden

* Corresponding author.

Email address: shush@ifm.liu.se. 


\begin{abstract}
The performance of hybrid solar cells composed of polymer and $\mathrm{ZnO}$ is mainly hindered by the defects of $\mathrm{ZnO}$. Here, we investigate the effects of $\mathrm{ZnO}$ nanoparticle surface modification with poly(ethylene oxide) (PEO) on the performance of bulk heterojunction hybrid solar cells based on poly[2-methoxy-5-(2'-ethyl-hexyloxy)-1,4-phenylene vinylene] (MEH-PPV) and $\mathrm{ZnO}$ nanoparticles. The reference device using $\mathrm{ZnO}$ nanoparticles as electron acceptor shows an open-circuit voltage $\left(V_{\mathrm{OC}}\right)$ of $0.83 \mathrm{~V}$, a shortcircuit current $\left(J_{\mathrm{SC}}\right)$ of $3.00 \mathrm{~mA} / \mathrm{cm}^{2}$, a fill factor $(\mathrm{FF})$ of 0.46 and a power conversion efficiency (PCE) of $1.15 \%$. After modification with very small amount of PEO, the PCE will be enhanced, which is attributed to less surface traps of $\mathrm{ZnO}$ nanoparticles with PEO modification. With optimized PEO (0.05\%) modified $\mathrm{ZnO}$ nanoparticles as electron acceptors, the device typically shows a $V_{\mathrm{OC}}$ of $0.86 \mathrm{~V}$, a $J_{\mathrm{SC}}$ of $3.84 \mathrm{~mA} / \mathrm{cm}^{2}$, a FF of 0.51 and a PCE of $1.68 \%$ due to less recombination loss of carriers, smaller series resistance, and improved the electrical coupling between $\mathrm{ZnO}$ nanoparticle and MEH-PPV. However, further increase PEO content to $0.3 \%$ will deteriorate device performance. Keywords: Hybrid solar cells, Surface modification, Trap, ZnO
\end{abstract}




\section{Introduction}

Polymer solar cells have been attractive candidates for green energy sources due to their potential advantages of low cost and large area processing [1-7]. The bulk heterojunction structure composed of interpenetrating network of polymer donor and electron acceptor has greatly promoted the development of polymer solar cells [8]. In the past two decades, a large variety of polymer donor materials have been tested [9-15]. In contrast to polymer donors, the diversity of electron acceptors remains rather small. Both inorganic and organic electron acceptors are used, the latter are mainly fullerene derivatives [16-18]. Although power conversion efficiency (PCE) of polymer solar cells with these fullerene derivatives electron acceptors reached up to $9 \%$, the complicated synthesis process and easy oxidation of fullerene in ambient still hinder their practical application [17-20]. Alternatively, inorganic nanocrystals such as $\mathrm{CdSe}, \mathrm{TiO}_{2}$ and $\mathrm{ZnO}$ can be used as electron acceptors combined with polymer donor in hybrid solar cells, which exhibit higher electron mobility and ambient stability with low cost [21-27]. Among these inorganic nanocrystals, $\mathrm{ZnO}$ is believed to be one of the most promising electron acceptors due to its environmental friendliness and low crystallization temperature. However, the intrinsic surface defects of $\mathrm{ZnO}$ nanocrystals make the final power conversion efficiency of hybrid solar cells lower than their fullerene based counterparts. These defects would trap photo-excited electrons, which not only enlarges series resistance $\left(R_{\mathrm{S}}\right)$ for electron transport and weaken electronic coupling with polymer donor in hybrid solar cells, but also results in severe back charge recombination due to the lower energy offset between the trap state and highest occupied electron orbit (HOMO) of polymer donor. Surface modification of $\mathrm{ZnO}$ surface using various organic 
molecules with functional groups is an effective way to passivate the surface traps [28, 29]. Currently, much attention has been paid to investigate the effects of surface modified $\mathrm{ZnO}$ as electron transport layer on polymer solar cells containing fullerene derivatives as electron acceptors. Hau et al. used a carboxylic acid functionlized fullerene to modify the surface of $\mathrm{ZnO}$ electron transport layer, which reduced the surface defects, improved electronic coupling of $\mathrm{ZnO} /$ organic layer and consequently improved the short circuit current density $\left(\mathrm{J}_{\mathrm{SC}}\right)$ and fill factor $(\mathrm{FF})$ of the device [28]. Hsieh et al. inserted a crosslinked fullerene between $\mathrm{ZnO}$ electron transport layer and active layer, which can also effectively passivate the shunts in $\mathrm{ZnO}$ film, restrain the back charge recombination and improve the device performance [29]. However, little efforts were paid to investigate the effects of surface modification of $\mathrm{ZnO}$ nanoparticles on bulk heterojunction hybrid solar cells based on polymers (as electron donor) and $\mathrm{ZnO}$ (as electron acceptor).

Herein, we report enhanced performance of bulk heterojunction hybrid solar cells composed of poly[2-methoxy-5-(2'-ethyl-hexyloxy)-1,4-phenylene vinylene] (MEHPPV) and $\mathrm{ZnO}$ by using poly(ethylene oxide) (PEO) modified $\mathrm{ZnO}$ nanoparticles as electron acceptors where PEO molecules coordinate to the surfaces of $\mathrm{ZnO}$ nanoparticles by sharing the lone electron pairs of oxygen in PEO with ZnO. In this case, the surface traps of $\mathrm{ZnO}$ nanoparticles are effectively passivated, which provide improved electrical coupling between $\mathrm{ZnO}$ and polymer as well as paths for electron transport and collection. The restrained trap-assisted recombination loss of carriers and reduced $R_{\mathrm{S}}$ contribute to improved performance of bulk heterojunction hybrid solar cells.

\section{Experimental}




\subsection{Synthesis of ZnO nanoparticles.}

MEH-PPV was purchased from Canton OLEDKING Optoelectronic Materials Co. Ltd. and PEO (weight average molecular weight $\left(\mathrm{M}_{\mathrm{w}}\right)=600$ 000) was purchased from BDH Chemicals.

$\mathrm{ZnO}$ was synthesized following the previous work [30]. $4 \mathrm{~g}$ of zinc acetate dihydrate (>99\%) was dissolved in $160 \mathrm{~mL}$ methanol at $60^{\circ} \mathrm{C}$ under vigorous stirring. $2 \mathrm{~g}$ of $\mathrm{KOH}$ (>85\%) was dissolved in $80 \mathrm{~mL}$ methanol. The $\mathrm{KOH}$ solution was dropped into the zinc acetate dihydrate solution in 10 min under vigorous stirring. The solution temperature was held at $60{ }^{\circ} \mathrm{C}$ and stirred for $4 \mathrm{~h}$, and then the heating and stirring were removed to allow particles to precipitate for additional $12 \mathrm{~h}$. The precipitate was cleaned by centrifugation of the dispersion and washed twice with $50 \mathrm{~mL}$ of methanol. The washed $\mathrm{ZnO}$ nanoparticles were dissolved in chlorobenzene (CB) to form $70 \mathrm{mg} / \mathrm{ml} \mathrm{ZnO} \mathrm{CB}$ solution. Surface modification of $\mathrm{ZnO}$ by PEO is achieved by adding the desired amount of PEO molecules into ZnO solution.

\subsection{Fabrication of hybrid solar cells.}

The device used in this work has a structure of ITO/PEDOT:PSS/poly[2-methoxy-5(2'-ethyl-hexyloxy)-1,4-phenylene vinylene] (MEH-PPV):PEO modified ZnO/Al. ITOcoated glass substrates were first cleaned with detergent and deionized water, then dried by nitrogen flow. A $45 \mathrm{~nm}$ thick PEDOT:PSS layer was spin coated on top of the ITO substrates as hole transport layer. A solution containing a mixture of MEH-PPV:ZnO (1:3, weight ratio) or MEH-PPV:PEO modified ZnO in chlorobenzene (CB):methonal (9:1, volume ratio) was spin-cast on top of the hole transport layer to produce a 80-nm-thick active layer. Finally, Al $(80 \mathrm{~nm})$ was deposited atop the active layer by thermal 
evaporation in a vacuum of $4 \times 10^{-6}$ Torr to complete the device fabrication. The cell active area was $5 \mathrm{~mm}^{2}$, which was defined by the overlapping area of the ITO and Al electrodes. The solar cells were characterized using a Keithley 2400 source meter under simulated AM 1.5G solar illumination $\left(100 \mathrm{~mW} \mathrm{~cm}^{-2}\right)$, with a GG $420 \mathrm{~nm}$ UV filter between the light source and the solar cells. External quantum efficiency (EQE) of the devices was collected by a Keithley 485 picoammeter under illumination of monochromatic light at short circuit condition.

\subsection{Other characterization.}

The thickness of MEH-PPV:PEO modified ZnO layer was measured using a Dektak 6M Stylus Profiler. Atomic force microscopy (AFM) images were recorded on Dimension 3100 system (Digital Instruments/Veeco) in tapping-mode. The dynamic light scattering experiment was performed on ALV light scattering system. Steady-state emission (PL) spectra of MEH-PPV:PEO modified ZnO blend films on glass substrate were recorded as follows: an Oriel optical liquid light guide was located as close to the sample as possible, and connected to the entrance slit of the spectrometer. A Newton EM-CCD Si array detector cooled to $-60{ }^{\circ} \mathrm{C}$ in conjunction with a Shamrock sr 303i spectrograph from Andor Tech. served as the emission detection system. The system was wavelength calibrated by an Argon lamp to a resolution higher than $0.5 \mathrm{~nm}$.

Transient absorption measurements (TA) were carried out by a standard pump-probe setup. In brief: laser pulses ( $800 \mathrm{~nm}, 80 \mathrm{fs}$ pulse length, $1 \mathrm{kHz}$ repetition rate) were generated by a femtosecond laser system (Mai-Tai) with a regenerative amplifier (Spitfire, both Spectra physics). The pulses were converted by using an optical parametric amplifiers (Topas, Light conversion) to $440 \mathrm{~nm}$ (excitation) and $575 \mathrm{~nm}$ (probe). In order 
to construct transient absorption signal, every second excitation pulse is blocked. Hence the probe pulse intensity can be recorded by a photodiode for the excited and non-excited sample. Transient absorption measurements were carried out on MEH-PPV:ZnO films without electrolyte and electrodes, placed in the nitrogen atmosphere. The samples were excited by the photon flux of $5 \times 10^{12}$ photons $/ \mathrm{cm}^{2}$ (corresponds to $\sim 2 \mu \mathrm{J} / \mathrm{cm}^{2}$ ).

\section{Results and discussion}

Fig. 1 shows the chemical structures of polymer donor MEH-PPV and surface modifier PEO. The effects of PEO modification to $\mathrm{ZnO}$ nanoparticle surface on the performance of the hybrid solar cells are investigated. Fig. 2 shows the illuminated J-V curves of the devices with various amounts of PEO surface modifier under $100 \mathrm{~mW} / \mathrm{cm}^{2}$ of AM 1.5G condition with performance parameters listed in Table 1 . The reference device without PEO shows an open-circuit voltage $\left(V_{\mathrm{OC}}\right)$ of $0.83 \mathrm{~V}$, a $J_{\mathrm{SC}}$ of $3.0 \mathrm{~mA} / \mathrm{cm}^{2}$, an FF of 0.46 , giving a final PCE of $1.15 \%$. The device performance was considerably improved when PEO modified $\mathrm{ZnO}$ is used as electron acceptor. The optimum device is achieved when using $0.05 \%$ PEO modified $\mathrm{ZnO}$ (weight ratio of $\mathrm{PEO}$ to $\mathrm{ZnO}$ ) as electron acceptor, which displays a $V_{\mathrm{OC}}$ of $0.86 \mathrm{~V}$, a $J_{\mathrm{SC}}$ of $3.84 \mathrm{~mA} \mathrm{~cm}^{-2}$, an FF of 0.51 and a PCE of 1.68\%. However, further increase PEO loading would degrade the device performance. Device with PEO content of $0.3 \%$ showed a decreased $J_{\mathrm{SC}}$ of $2.21 \mathrm{~mA} \mathrm{~cm}^{-2}$ and a reduced FF of 0.39 , giving a final PCE of $0.74 \%$. The origin of performance variation can be revealed by analyzing series resistance $\left(R_{\mathrm{S}}\right)$ and shunt resistance $\left(R_{\mathrm{sh}}\right)$ of the hybrid solar cells extracted from the illuminated $J-V$ characteristics. Twelve devices in each configuration were fabricated and the averaged device performance parameters are summarized in Table 1 . The optimum device using modified $\mathrm{ZnO}$ with $0.05 \% \mathrm{PEO}$ as 
electron acceptor shows a smaller $R_{\mathrm{S}}$ and higher $R_{\mathrm{sh}}\left(R_{\mathrm{S}}=37 \Omega \mathrm{cm}^{2}, R_{\mathrm{sh}}=1.8 \mathrm{k} \Omega \mathrm{cm}^{2}\right)$ compared to the reference device $\left(R_{\mathrm{S}}=70 \Omega \mathrm{cm}^{2}, R_{\mathrm{sh}}=1.05 \mathrm{k} \Omega \mathrm{cm}^{2}\right)$. The reduced $R_{\mathrm{S}}$ of the device with PEO modified $\mathrm{ZnO}$ as electron acceptors is favorable for charge transport and collection, which explains the improved FF and $J_{\mathrm{SC}}$. The increased $R_{\mathrm{sh}}$ indicates restrained recombination loss of charge carriers due to the current leakage pathways in the bulk active layer. This is verified by dark $J$ - $V$ curves as shown in Fig. 2a. It is obvious that the device with $0.05 \%$ PEO modified $\mathrm{ZnO}$ as electron acceptors shows considerably restrained leakage current and higher built-in potential at forward bias compared to the reference device, resulting in an enhanced $V_{\mathrm{OC}}$. When PEO content is increased up to $0.3 \%$, however, all the device parameters degrade with $R_{\mathrm{S}}$ increased to $90 \Omega \mathrm{cm}^{2}$ and $R_{\mathrm{sh}}$ decreased to $0.99 \mathrm{k} \Omega \mathrm{cm}^{2}$ due to large energy barrier for charge collection and pronounced carrier recombination within the device. Fig. $2 \mathrm{~b}$ shows external quantum efficiency (EQE) of the devices, that is, the efficiency of electrons generated per incident photon increases first and then decreases with the increment of PEO content. The maximum EQE value appears in $0.05 \%$ PEO modified device over the whole absorption spectrum of MEH-PPV.

Because of very high surface-to-volume ratio of nanoparticles, surface states play an important role in such materials. It is generally accepted that surface traps of $\mathrm{ZnO}$ nanocrystals have a significant adverse effect on the performance of hybrid solar cells. [31,32]. Energy of the traps is usually located within the bandgap of $\mathrm{ZnO}$ as schematically shown in Fig. 3. Electrons which are transferred from MEH-PPV will be efficiently trapped and consequently $R$ s for electron transport is increased. Due to the energy barrier between the trap states of $\mathrm{ZnO}$ and the top electrode $\mathrm{Al}$ for electron 
collection, the trapped electrons are likely to recombine with holes in the HOMO level of MEH-PPV, leading to leakage current or a smaller $R_{\mathrm{sh}}$. When PEO is used to modify $\mathrm{ZnO}$ nanocrystal surface, however, PEO molecules coordinate to the surface of $\mathrm{ZnO}$ by sharing the lone electron pair of oxygen in $\mathrm{PEO}$ with $\mathrm{ZnO}$, and therefore degenerate the population of trap states [32]. In this case, the trapping of electrons and $R_{\mathrm{S}}$ are considerably decreased, which lead to enhanced $J_{\mathrm{sc}}$ and FF. Moreover, the back charge transfer recombination from trap states to HOMO level of MEH-PPV is also restrained, which contributes to increased $R_{\mathrm{sh}}$ and $V_{\mathrm{oc}}$.

The effect of PEO on the topography of the active layer is investigated with an Atomic Force Microscopy (AFM). As depicted in Fig. 4, MEH-PPV:0.05\% PEO modified $\mathrm{ZnO}$ film shows similar smooth surface morphology to that of the pristine MEH-PPV:ZnO film, which ensures comparable contact with Al cathode and contact resistance. However, when PEO content is further increased up to $0.3 \%$, the active layer shows very rough surface morphology. The root mean square (RMS) roughness of MEHPPV:0.3\% PEO modified $\mathrm{ZnO}$ film is increased from $4 \mathrm{~nm}$ to $40 \mathrm{~nm}$ compared to the MEH-PPV:ZnO film. After modification, the surface of $\mathrm{ZnO}$ nanoparticles becomes more hydrophilic [32], which causes larger $\mathrm{ZnO}$ aggregates in nonpolar CB:methanol solution before film formation, as can be seen from dynamic light scattering (DLS) results in Fig. 5. Moreover, the more hydrophilic surface of PEO modified $\mathrm{ZnO}$ nanoparticle renders them less compatible with MEH-PPV in solution. These two factors lead to large phase separation and rough surface of MEH-PPV:PEO modified ZnO film. First of all, this reduces the interface area between MEH-PPV and ZnO domains, and consequently decreases the exciton dissociation efficiency due to a short exciton 
diffusion length (about $10 \mathrm{~nm}$ ). To validate this assumption, PL spectra were recorded for the MEH-PPV:PEO modified ZnO films as shown in Fig. 6. As can be seen, the quenching of the intrinsic emission from MEH-PPV by $\mathrm{ZnO}$ was obviously weakened when the PEO content is $0.3 \%$, which indicates less interface area between MEH-PPV and $\mathrm{ZnO}$ for exciton dissociation. Secondly, the insulating PEO molecules may form a barrier layer restraining exciton dissociation and the charge transport between $\mathrm{ZnO}$ nanoparticles, which is evidenced by increased series resistance and reduced fill factor with PEO content up to $0.3 \%$. Furthermore, pinholes are often produced within the rough active layer, which allow the evaporated aluminium atoms to be in direct contact with anode and consequently result in local shunting. The poor contact between cathode $\mathrm{Al}$ and the rough active layer is another possible reason for the shunts. These shunts in rougher active layer greatly reduced the $R_{\mathrm{sh}}$ to $0.99 \mathrm{k} \Omega \mathrm{cm}^{2}$ and thus increased the recombination loss for the free carriers. Therefore, as the PEO content was increased up to $0.3 \%$, the reduced exciton dissociation efficiency, the restrained electron transport and increased leakage current lead to reduced device performance.

In order to investigate the effect of PEO addition on the charge transfer dynamics between MEH-PPV and PEO modified ZnO, we carried out transient absorption spectroscopy measurements. The observed signal (see Fig. 7) is dominated by the MEHPPV absorption bleach, which reflects the concentration of the excitons in the polymer [33]. The pristine MEH-PPV films on glass, shows a longest exciton lifetime of 180 ps. The exciton lifetime is sharply decreased when $\mathrm{ZnO}$ is incorporated into MEH-PPV matrix due to electron transfer from LUMO of MEH-PPV to that of ZnO. When PEO content is lower than $0.05 \%$, similar exciton decay dynamics are observed for $\mathrm{MEH}$ - 
PPV:PEO modified ZnO blends. It indicates the charge transfer process is not influenced by small PEO content based on the fact these two films show similar surface morphology and microstructure. However, MEH-PPV:0.3\%PEO modified $\mathrm{ZnO}$ film shows a prolonged exciton lifetime of 85 ps, which originates from inefficient exciton dissociation. As previously discussed, the large phase separation between $0.3 \%$ PEO modified ZnO and MEH-PPV reduces the exciton dissociation efficiency. Besides, too much PEO content may also prohibit the electron transfer from MEH-PPV to $\mathrm{ZnO}$. These lead to reduced $J_{\mathrm{SC}}$ and $\mathrm{FF}$ of the device using $0.3 \%$ PEO modified $\mathrm{ZnO}$ as electron acceptor.

\section{Conclusion}

In conclusion, the effects of PEO modified $\mathrm{ZnO}$ as electron acceptor on the performance of hybrid solar cells composed of MEH-PPV and ZnO are investigated. It is found that the device using small amount of PEO $(<0.05 \%)$ modified $\mathrm{ZnO}$ as electron acceptor shows considerably reduced series resistance and increased shunt resistance due to the passivated surface traps of $\mathrm{ZnO}$ electron acceptor. As a result, the device performance is improved due to favorable electron transport and restrained back charge transfer recombination. The optimum device using $0.05 \%$ PEO modified $\mathrm{ZnO}$ as electron acceptor shows a $V_{\text {oc }}$ of $0.86 \mathrm{~V}$, a $J_{\mathrm{sc}}$ of $3.84 \mathrm{~mA} / \mathrm{cm}^{2}$, a FF of 0.51 and a PCE of $1.68 \%$.

\section{Acknowledgements}

The authors are grateful to Swedish energy agency (Energimyndigheten), the Swedish Research Council (VR), the Knut, Alice Wallenberg Foundation, Crafoord foundation and VINNOVA for the financial supports. 


\section{References}

[1] S. R. Dupont, M. Oliver, F. C. Krebs, R. H. Dauskardt, Interlayer adhesion in roll-toroll processed flexible inverted polymer solar cells, Solar Energy Material and Solar Cells 97 (2012) 171-175.

[2] R. Søndergaard, M. Hösel, D. Angmo, T. T. Larsen-Olsen, F. C. Krebs, Roll-to-roll fabrication of polymer solar cells, Materials Today 15 (2012) 36-49.

[3] F. C. Krebs, Fabrication and processing of polymer solar cells: A review of printing and coating techniques, Solar Energy Materials and Solar Cells 93 (2009) 394-412.

[4] C. M. Amb, M. R. Craig, U. Koldemir, J. Subbiah, K. R. Choudhury, S. A. Gevorgyan, M. Jørgensen, F. C. Krebs, F. So, J. R. Reynolds, Aesthetically Pleasing Conjugated Polymer:Fullerene Blends for Blue-Green Solar Cells Via Roll-to-Roll Processing, ACS Applied Materials and Interfaces 4 (2012) 1847-1853.

[5] F. C. Krebs, S. A. Gevorgyan, J. Alstrup, A roll-to-roll process to flexible polymer solar cells: model studies, manufacture and operational stability studies, Journal of Materials Chemistry 19 (2009) 5442-5451.

[6] F. C. Krebs, J. Fyenbo, D. M. Tanenbaum, S. A. Gevorgyan, R. Andriessen, B. Remoortere, Y. Galagan, M. Jørgensen, The OE-A OPV demonstrator anno domini, Energy and Environmental Science 4 (2011) 4116-4123.

[7] F. C. Krebs, T. D. Nielsen, J. Fyenbo, M. Wadstrøm, M. S. Pedersen, Manufacture, integration and demonstration of polymer solar cells in a lamp for the "Lighting Africa” initiative, Energy \& Environmental Science 3 (2010) 512-525. 
[8] G. Yu, J. Gao, J. C. Hummelen, F. Wudl, A. J. Heeger, Polymer Photovoltaic Cells: Enhanced Efficiencies via a Network of Internal Donor-Accetor Heterojunctions, Science 270 (1995) 1789-1791.

[9] F. Zhang, W. Mammo, L. M. Andersson, S. Admassie, M. R. Andersson, O. Inganäs, Low-Bandgap Alternating Fluorene Copolymer/Methanofullerene Heterojunctions in Efficient Near-Infrared Polymer Solar Cells, Advanced Materials 18 (2006) 21692173.

[10] N. Blouin, A Michaud, M. Leclerc, A Low-Bandgap Poly(2,7-Carbazole) Derivative for Use in High-Performance Solar Cells, Advanced Materials 19 (2007) 2295-2330.

[11] J. Hou, H.-Y. Chen, S. Zhang, R. I. Chen, Y. Yang, Y. Wu, G. Li, Synthesis of a Low Band Gap Polymer and Its Application in Highly Efficient Polymer Solar Cells, Journal of American Chemistry Society 131 (2009) 15586-15587.

[12] H.-Y. Chen, J. Hou, S. Zhang, Y. Liang, G. Yang, Y. Yang, L. Yu, Y. Wu, G. Li, Polymer solar cells with enhanced open-circuit voltage and efficiency, Nature Photonics 3 (2009) 649-653.

[13] Y. Liang, Z. Xu, J. Xia, S.-T. Tsai, Y. Wu, G. Li, C. Ray, L. Yu, For the Bright Future-Bulk Heterojunction Polymer Solar Cells with Power Conversion Efficiency of 7.4\%, Advanced Materials 22 (2010) 1-4.

[14] E. Wang, L. Tao, Z. Wang, S. Hellström, F. Zhang, O. Inganäs, M. R. Andersson, An Easily Synthesized Blue Polymer for High-Performance Polymer Solar Cells, Advanced Materials 22 (2010) 5240-5244.

[15] Y. Huang , X. Guo, F. Liu , L. Huo , Y. Chen , T. P. Russell, C. C. Han, Y. Li, J. Hou, Improving the Ordering and Photovoltaic Properties by Extending-Conjugated 
Area of Electron-Donating Units in Polymers with D-A Structure, Advanced Materials 24 (2012) 3383-3389.

[16] N. S. Sariciftci, L. Smilowitz, A. J. Heeger, and F. Wudl, Photoinduced Electron Transfer from a Conducting Polymer to Buckminsterfullerene, Science 258 (1992) 1474-1476.

[17] J. C. Hummelen, B. W. Knight, F. LePeq, F. Wudl, Preparation and Characterization of Fulleroid and Methanofullerene Derivatives, Journal of Organic Chemistry 60 (1995) 532-538.

[18] Y. He, H.-Y. Chen, J. Hou, Y. Li, Indene-C60 Bisadduct: A New Acceptor for HighPerformance Polymer Solar Cells, Journal of American Chemistry Society 132 (2010) 1377-1382.

[19] M. O. Reese, A. M. Nardes, B. L. Rupert, R. E. Larsen, D. C. Olson, M. T. Lloyd, S. E. Shaheen, D. S. Ginley, G. Rumbles, N. Kopidakis, Photoinduced Degradation of Polymer and Polymer-Fullerene Active Layers: Experiment and Theory, Advanced Functional Materials 20 (2010) 3476-3483.

[20] Z. He, Z. Mei, S. Su, M. Xu, H. Wu, Y. Cao, Enhanced power-conversion efficiency in polymer solar cells using an inverted device structure, Nature Photonics 6 (2012) 591-595.

[21] W. U. Huynh, J. J. Dittmer, A. P. Alivisatos, Hybrid Nanorod-Polymer Solar Cells, Science 295 (2002) 2425-2427.

[22] Baoquan Sun , Eike Marx , and Neil C. Greenham, Photovoltaic Devices Using Blends of Branched CdSe Nanoparticles and Conjugated Polymers, Nano Letters 3 (2003) 961-963. 
[23] Y.-Y. Lin, T.-H. Chu, S.-S. Li, C.-H. Chuang, C.-H. Chang, W.-F. Su, C.-P. Chang, M.-W. Chu, C.-W. Chen, Interfacial Nanostructuring on the Performance of Polymer/TiO2 Nanorod Bulk Heterojunction Solar Cells, Journal of American Chemistry Scoiety 131 (2009) 3644-3649.

[24] Y.-Y. Lin, T.-H. Chu, C.-W. Chen, W.-F. Su, Improved performance of polymer/TiO2 nanorod bulk heterojunction photovoltaic devices by interface modification, Applied Physics Letters 92 (2008) 053312.

[25] W. J.E. Beek, M. M. Wienk, R. A. J. Janssen, Efficient Hybrid Solar Cells From Zinc Oxide Nanoparticles and a Conjugated Polymer, Advanced Materials 16 (2004) 1009-1013.

[26] S. Shao, J. Liu, B. Zhang, Z. Xie, L. Wang, Enhanced stability of zinc oxide-based hybrid polymer solar cells by manipulating ultraviolet light distribution in the active layer, Applied Physics Letters 98 (2011) 203304.

[27] J. Huang, Z. Yin, Q. Zheng, Applications of ZnO in organic and hybrid solar cells, Energy Environment Science 4(2011) 3861-3877.

[28] Steven K. Hau,a Hin-Lap Yip,a Orb Acton,a Nam Seob Baek,a Hong Maa and Alex K.-Y. Jen Interfacial modification to improve inverted polymer solar cells, Journal of Material Chemistry 2008, 18, 5113-5119.

[29] C.-H. Hsieh, Y.-J. Cheng, P.-J. Li, C.-H. Chen, M. Dubosc, R.-M. Liang, C.-S. Hsu Highly Efficient and Stable Inverted Polymer Solar Cells Integrated with a CrossLinked Fullerene Material as an Interlayer, Journal of American Chemistry Scoiety 132 (2010) 4887-4893. 
[30] W. J. E. Beek, M. M. Wienk, M. Kemerink, X. Yang, R. A. J. Janssen, Hybrid Zinc Oxide Conjugated Polymer Bulk Heterojunction Solar Cells, Journal of Physical Chemistry B 109 (2005) 9505-9516.

[31] A. Dijken, E. A. Meulenkamp, D. Vanmaekelbergh, A. Meijerink, Influence of Adsorbed Oxygen on the Emission Properties of Nanocrystalline ZnO Particles, Journal of Physical Chemistry B 104 (2000) 4355-4360.

[32] S. Shao, K. Zheng, T. Pullerits, F. Zhang, Enhanced Performance of Inverted Polymer Solar Cells by Using Poly(ethylene oxide) Modified $\mathrm{ZnO}$ as Electron Transport Layer, ACS Applied Materials \& Interfaces 5 (2013) 380-385.

[33] I. G. Scheblykin, A. Yartsev, T. Pullerits, V. Gulbinas, V. Sundström, Excited State and Charge Photogeneration Dynamics in Conjugated Polymers, Journal of Physical Chemistry B 111 (2007) 6303-6321. 


\section{Captions}

Fig. 1. Chemical structures of (a) MEH-PPV and (b) PEO.

Fig. 2. (a) The illuminated $J$ - $V$ characteristics (open symbols) and dark $J$ - $V$ characteristics (filled symbols), (b) EQE data of hybrid solar cells composed of MEH-PPV: PEO modified ZnO blends.

Fig. 3. The schematic diagrams of energy level of the devices using (a) pristine ZnO, and (b) PEO modified $\mathrm{ZnO}$ as electron acceptor.

Fig. 4. The topography images of MEH-PPV:PEO modified $\mathrm{ZnO}$ films (a) ZnO, (b) 0.05\% PEO modified ZnO, and (c) 0.3\% PEO modified ZnO.

Fig. 5. DLS results of $0 \%$ and $0.3 \%$ PEO modified $\mathrm{ZnO}$ in CB:Methanol solution.

Fig. 6. PL spectra of MEH-PPV:PEO modified ZnO blend films on top of glass substrates.

Fig. 7. TA spectra of MEH-PPV:PEO modified ZnO blend films on top of glass substrates.

Table 1 The performance parameters of the hybrid solar cells based on MEH-PPV:PEO modified $\mathrm{ZnO}$ blends.

\begin{tabular}{ccccccc}
\hline $\begin{array}{c}\mathrm{PEO} / \mathrm{ZnO} \\
(\mathrm{wt} \%)\end{array}$ & $\begin{array}{c}V_{\mathrm{OC}} \\
(\mathrm{V})\end{array}$ & $\begin{array}{c}J_{\mathrm{SC}} \\
\left(\mathrm{mA} \mathrm{cm}^{-2}\right)\end{array}$ & $\mathrm{FF}$ & $\begin{array}{c}R_{\mathrm{S}} \\
\Omega \mathrm{cm}^{2}\end{array}$ & $\begin{array}{c}R_{\mathrm{P}} \\
\mathrm{k} \Omega \mathrm{cm}^{2}\end{array}$ & PCE (\%) \\
\hline 0 & 0.83 & 3.00 & 0.46 & 70 & 1.05 & 1.15 \\
0.01 & 0.85 & 3.64 & 0.49 & 50 & 2.00 & 1.52 \\
0.05 & 0.86 & 3.84 & 0.51 & 37 & 1.80 & 1.68 \\
0.3 & 0.90 & 2.11 & 0.39 & 91 & 0.99 & 0.74 \\
\hline
\end{tabular}


Fig.1

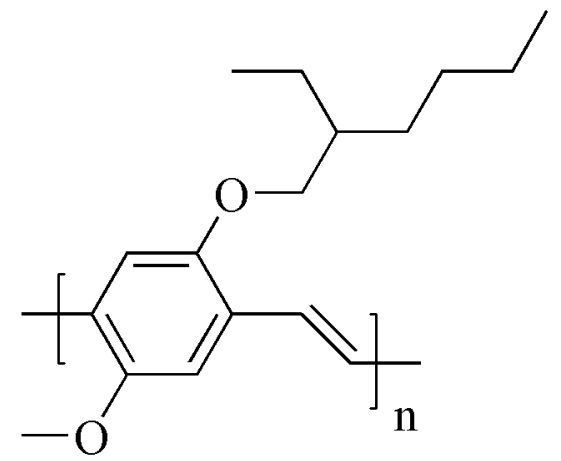

(a) MEH-PPV

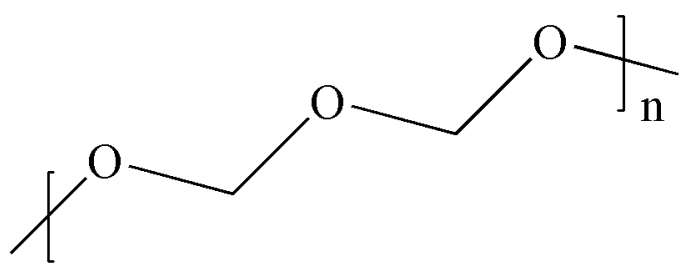

(b) PEO

Fig.2
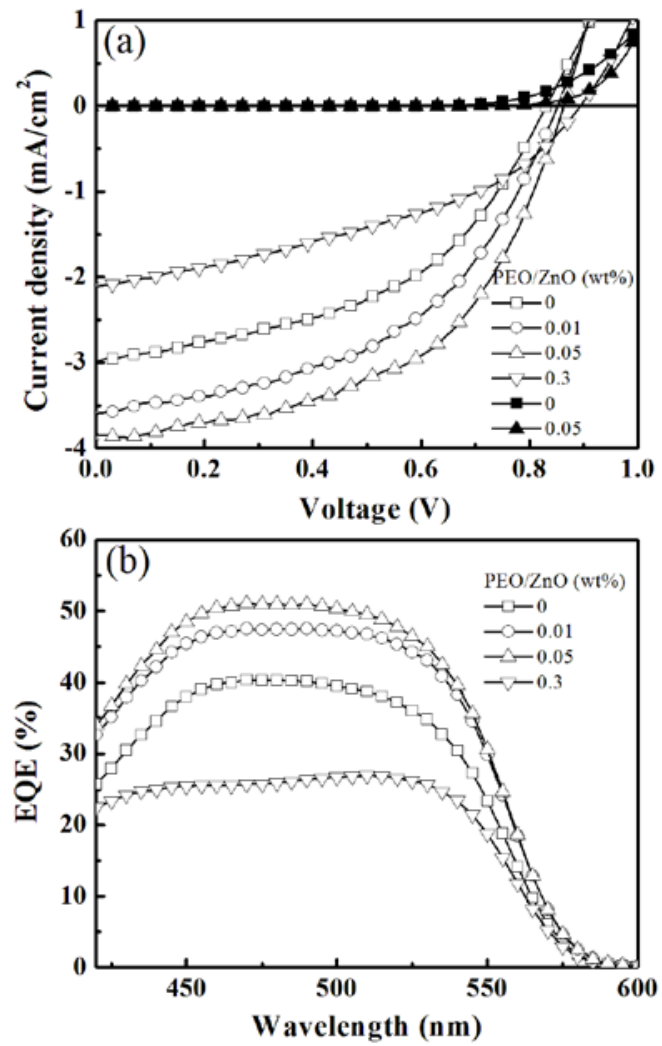
Fig.3

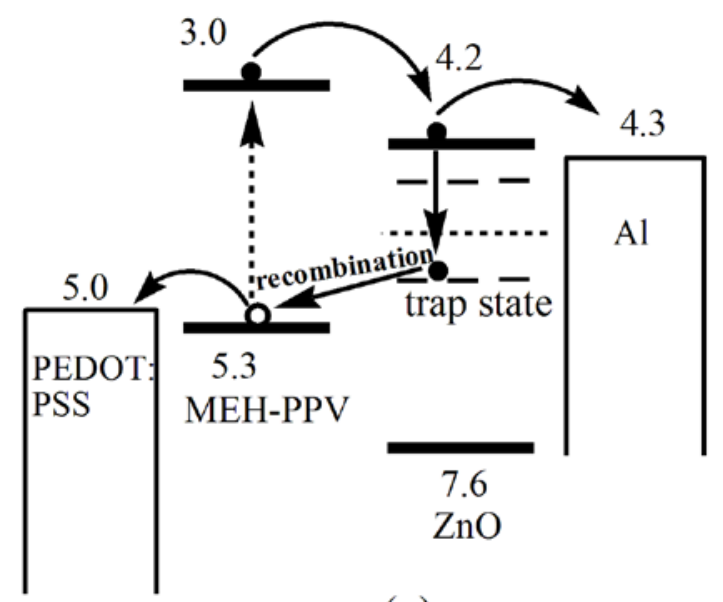

(a)

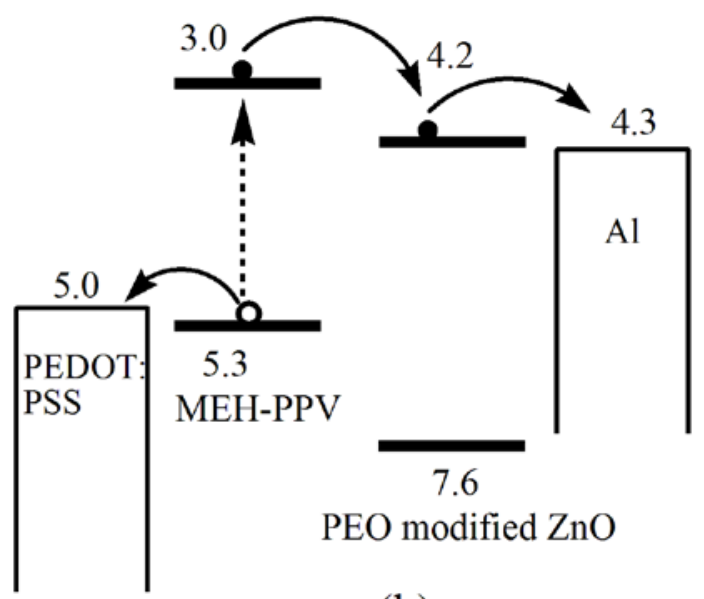

(b)

Fig.4
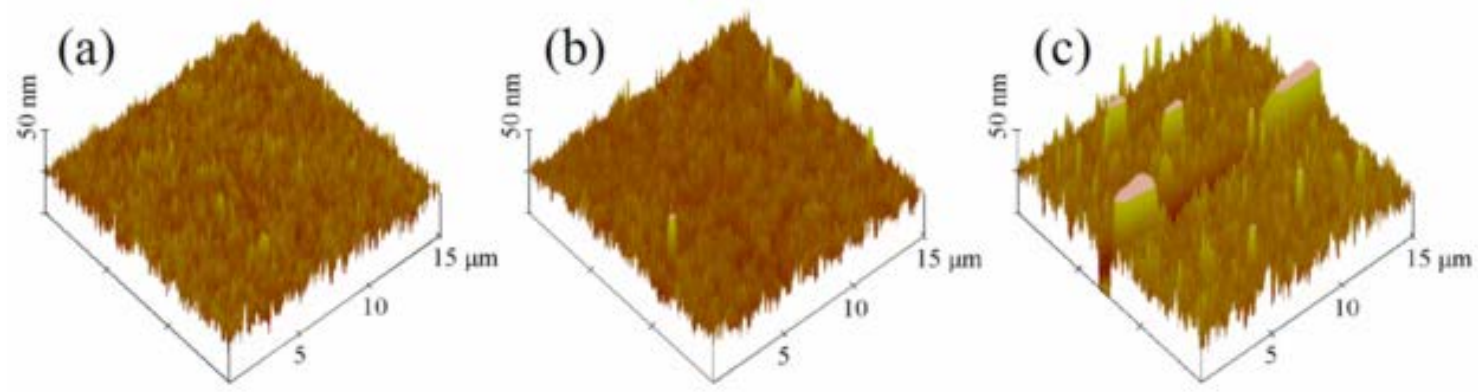
Fig.5

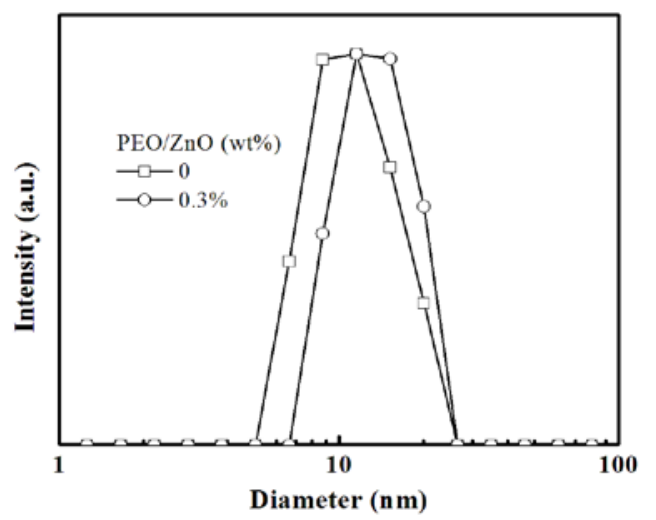

Fig.6

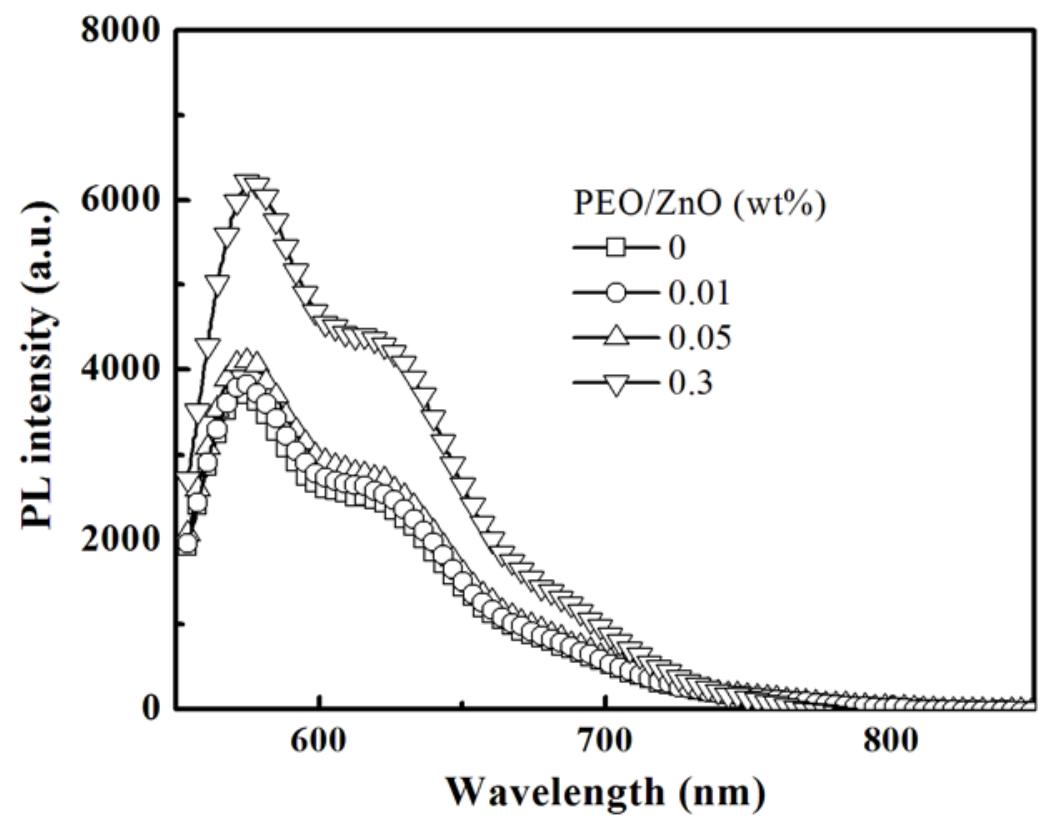


Fig.7

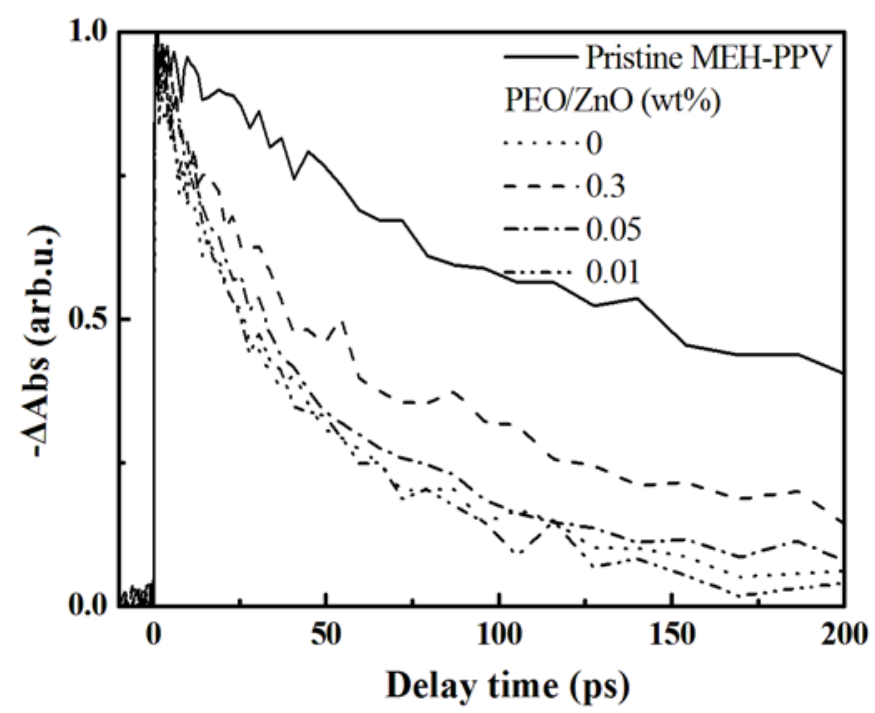

